\title{
PEMBUATAN TEKNOLOGI ROBOTIK DALAM DUNIA MILITER SEBAGAI MEDIA PEMANTAU DAN NEGOSIASI BERBASISKAN ARTIFICIAL INTELLIGENCE
}

\author{
Nanda Tommy Wirawan ${ }^{1 *}$, Defnizal ${ }^{1}$, Risa Nadia Ernes ${ }^{1}$ \\ ${ }^{1}$ Program Studi Sistem Komputer, Universitas Putra Indonesia YPTK Padang \\ email: nandatommyw@upiyptk.ac.id
}

\begin{abstract}
Negotiations in the release of hostages are the most important way in a rescue mission for hostages. If the officer is wrong in taking action in the negotiation process, the effect that can be caused is the safety threat of both the officer or personnel in charge and the safety of the hostage victims. The reason is the ineffectiveness of communication so that it always results in a shootout to complete the abduction. And the problem is resolved without communication between criminals and personnel. In this case, we designed a negotiating robot equipped with weapons so that the safety and security of the officers would also be a concern in carrying out their duties, both in the task of war against the enemy and in the task of freeing hostages. and officers who are responsible for the safety of the victims being taken, hostage. With this military robot, the monitoring can help military members or personnel in negotiating and monitoring without having to sacrifice lives.
\end{abstract}

Keywords: Arduino; FPV; GPS; Robot; Sensor.

\begin{abstract}
Abstrak: Negosiasi dalam pembebasan sandera merupakan cara terpenting dalam sebuah misi penyelamatan sandera, Jika petugas salah dalam mengambil tindakan dalam proses negosiasi maka efek yang dapat ditimbulkan adalah ancaman keselamatan baik petugas atau personil yang berwajib maupun keselamatan dari pihak korban yang disandera. Penyebabnya adalah tidak efektifnya komuniskasi sehingga mengakibatkan selalu terjadinya baku tembak untuk menyelesaikan penyandraan tersebut. Masalah terselesaikan tanpa ada komunikasi antara penjahat dan personil. Dalam hal tersebut kami merancang sebuah robot negosiasi yang dilengkapi dengan senjata agar keselamatan dan keamanan petugas juga menjadi perhatian dalam menjalankan tugas, baik dalam tugas perang melawan musuh maupun dalam tugas pembebasan sandera. Dalam hal pembebasan sandera perlu dilakukan berbagai cara agar mendapatkan kesepakatan terbaik antara musuh dan petugas yang berwajib guna keselamatan korban yang disandera. Dengan adanya robot militer pemantau ini dapat membantu anggota atau personil militer dalam melakukan negosiasi dan pemantauan tanpa harus mengorbankan nyawa.
\end{abstract}

Kata kunci: Arduino; FPV; GPS; Robot; Sensor. 
JURTEKSI (Jurnal Teknologi dan Sistem Informasi)

Vol. 6 No. 2, April 2020, hlm. 155 - 162

DOI: https://doi.org/10.33330/jurteksi.v6i2.538

Available online at http://jurnal.stmikroyal.ac.id/index.php/jurteksi
ISSN 2407-1811 (Print)

ISSN 2550-0201 (Online)

\section{PENDAHULUAN}

Perkembangan Ilmu pengetahuan dan teknologi semakin maju, terutama di bidang teknologi elektronika dan robotik yang mampu mempengaruhi kehidupan manusia agar lebih praktis dan simple [1]. Otomatisasi robot yang merupakan sebuah alat yang dapat digunakan sebagai pengganti tugas manusia memiliki beberapa kelebihan. Kelebihan tersebut salah satunya adalah dapat digunakan pada tempat-tempat yang berbahaya atau tempat yang beresiko tinggi bagi manusia. Pada bidang Militer merupakan salah satu contoh sistem pertahanan yang tentunya dalam menjalankan tugas banyak menghadapi hambatan. Hambatan yang dihadapi oleh militer banyak ragamnya, diantaranya dalam menjalankan tugas yang dihadapi untuk pengintaian yang kerap kali memakan korban jiwa, maka diperlukan sebuah terobosan baru dari segi teknologinya [2].

Seiring dengan berkembangnya teknologi robotik maka berkembang pula kualitas kehidupan manusia. Robot menjadi suatu perangkat yang sangat penting di dunia saat ini disebabkan robot dapat mengemban tugas dan fungsi yang sangat fleksibel dalam membantu pekerjaan manusia sehingga pekerjaan manusia bisa menjadi lebih mudah [3]. Robot merupakan sebuah alat mekanik yang dapat melakukan tugas fisik, baik menggunakan pengawasan dan kontrol manusia, ataupun menggunakan program yang telah didefinisikan terlebih dulu (kecerdasan buatan) [4]. Kecerdasan Buatan atau Artificial Intelegent (AI) adalah salah satu cabang ilmu pengetahuan yang membuat mesin menjadi cerdas, terutama dalam pemrograman computer [5], [6].

Terdapat tiga kata kunci yang menunjukkan ciri sebuah robot yaitu: reprogrammable (dapat diprogram kembali), multifunctional (multifungsi), dan move material, part, tools (mampu mendefinisikan tugas manipulator) [7].

Di dunia militer dan penanggulangan bencana, banyak muncul ide serta inovasi umumnya didasari pada keinginan yang kuat untuk mengurangi jumlah korban jiwa manusia pada berbagai tugas militer. Pada kebutuhan industri dan rumah tangga pada umumnya penggunaan robot didorong oleh keinginan untuk menjadikan robot sebagai pengganti pekerja manusia pada hal-hal yang sesuai dan menuntut untuk hal tersebut.

Mobile robot Merupakan jenis robot yang paling banyak digunakan contohnya kebutuhan rumah tangga dan bahkan pada industri [8]. Untuk dapat menjalankan tugasnya maka mobile robot yang dibangun harus mampu melakukan hal-hal sepert Melakukan pergerakan secara otomatis sehingga mampu menunjang kinerja manusia [9].

Aksi terorisme selain bermotif finansial juga berlandaskan perlawanan yang sifatnya politik idiologis, sehingga membutuhkan penanganan yang hatihati[10].

Keselamatan dan keamanan personil juga menjadi perhatian dalam menjalankan tugas, baik dalam tugas perang melawan musuh maupun dalam tugas pembebasan sandera. Dalam hal pembebasan sandera perlu dilakukan berbagai cara agar mendapatkan kesepakatan terbaik antara musuh dan petugas yang berwajib guna keselamatan korban yang disandera. Negosiasi dalam pembebasan sandera merupakan cara terpenting dalam sebuah misi penyelamatan sandera, Jika petugas salah dalam mengambil tindakan dalam proses negosiasi maka efek yang dapat ditimbulkan adalah ancaman keselamatan baik petugas atau personil yang berwajib 
JURTEKSI (Jurnal Teknologi dan Sistem Informasi)

Vol. 6 No. 2, April 2020, hlm. 155 - 162

DOI: https://doi.org/10.33330/jurteksi.v6i2.538

Available online at http://jurnal.stmikroyal.ac.id/index.php/jurteksi
ISSN 2407-1811 (Print)

ISSN 2550-0201 (Online) maupun keselamatan dari pihak korban yang disandera.

\section{METODE}

Tahapan metode penelitian dimulai dari: Mendefinisikan Ruang Lingkup Masalah. Ruang masalah yang akan diteliti harus ditentukan terlebih dahulu, karena tanpa mampu mendefinisikan serta menentukan batasan masalah yang akan diteliti, maka tidak akan didapat suatu solusi yang terbaik dari masalah tersebut. Mempelajari literatur, Untuk mencapai tujuan yang akan ditentukan, maka perlu dipelajari beberapa literatur-literatur yang digunakan. Kemudian literatur-literatur yang dipelajari tersebut diseleksi untuk dapat ditentukan literatur mana yang akan digunakan dalam penelitian.

Analisa sistem, Pada tahap ini, yaitu menganalisa semua hal yang berkaitan dalam perancangan Sistem. Desain sistem, Pada tahap desain, ditentukan unsur-unsur yang terkandung yang akan dituangkan kedalam pembuatan sistem robot. Perancangan sistem, Tahap ini bertujuan untuk merancang sistem yang akan dibuat, seperti: perancangan elektronika dan rancangan program.

Uji sistem,pada tahap uji sistem menggunakan software Arduino untuk pemrogramannya dengan bantuan alat downloader yang digunakan untuk mengisi program ke dalam mikrokontroler Arduino. Kemudian masingmasing modul diuji apakah berfungsi atau tidak. Implementasi, tahap implementasi bertujuan agar sistem robot bisa memproses data yang akan dikirimkan ke sistem kontrol supaya robot dapat bekerja dengan baik.

Tahap akhir adalah pengujian hasil, pengujian hasil dapat dilakukan setelah semua sistem berjalan dengan baik sehingga sistem robot mampu menjalankan perintah dengan baik sesuai dengan perintah yang diinginkan.

\section{HASIL DAN PEMBAHASAN}

\section{Desain Secara Umum}

Secara umum bentuk dari Sistem Teknologi Robotik Dalam Dunia Militer Sebagai Media Pemantau Dan Negosiasi Berbasiskan Artificial Intelligence digambarkan dengan menggunakan Blok Diagram.

\section{Blok Diagram}

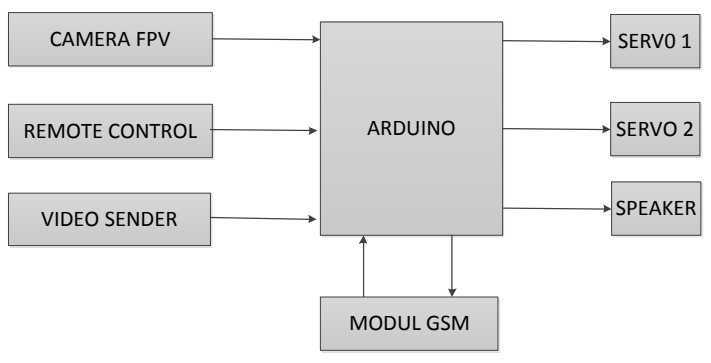

Gambar 1. Blok Diagram

Dari blok diagram 1 terlihat bahwa pusat pemprosesan data berada pada Arduino Uno, dimana Camera FPV, Remote Control dan Video Sender merupakan input yang akan diproses di Arduino Uno, yang akan memberikan output ke Servo 1 dan servo 2 untuk pergerakan kamera dan speaker sebagai media output untuk suara. Kemudian modul GSM akan berfungsi sebagai perangkat untuk mengirimkan informasi berupa panggilan dan SMS kepada User.

\section{Prinsip Kerja Sistem}

Secara umum sistem akan bekerja setelah mendapatkan tegangan dari batterai lippo dengan tegangan 12,4 Volt 2200 mAh. Dan akan menjalankan 
Available online at http://jurnal.stmikroyal.ac.id/index.php/jurteksi

perintah sesuai dengan instruksi berupa input data pada remote control, Modul GSM, Camera FPV, GPS, dan Video Sender. Modul GSM berfungsi sebagai media komunikasi robot yang akan mengirimkan informasi berupa SMS dan Panggilan Telepon. Apabila robot diaktifkan, robot akan dikendalikan melalui remote control, dan kamera akan bekerja sebagai media input untuk memantau keadaan yang terjadi di sekitar robot. Setelah robot mencapai target maka proses negosiasi dapat di lakukan dengan komunikasi antara User dengan Musuh melalui media Input berupa MIC dan Output Speaker yang dikirimkan melalui panggilan Telepon, dan GPS akan memberikan titik koordinat lokasi yang akan dikirim melalui SMS.

\section{Pengujian Sistem}

Pada gambar 2 terlihat sistem tampak dari arah depan dan arah belakang, pada bagian depan terdapat 1 camera yang berfungsi sebagai perangkat untuk memberikan informasi terhadap objek yang ada di depan robot, kemudian di bagian tengah robot terdapat speaker yang berfungsi sebagai output suara yang nantinya akan digunakan sebagai media komunikasi dengan musuh, kemudian Camera dan 2 buah servo, berfungsi sebagai media pemantau daerah sekitar robot, dengan memanfaatkan servo agar camera dapat diputar $180^{\circ}$ secara otomatis.

Pada gambar 3 tampak bagian belakang robot yang dilengkapi dengan camera yang berfungsi untuk mengetahui objek yang ada di bagian belakang robot. Kemudian baterai lippo dengan tegangan 12,4 Volt $2200 \mathrm{mAh}$ juga terpasang pada bagian belakang sebagai supply arus untuk sistem robot.

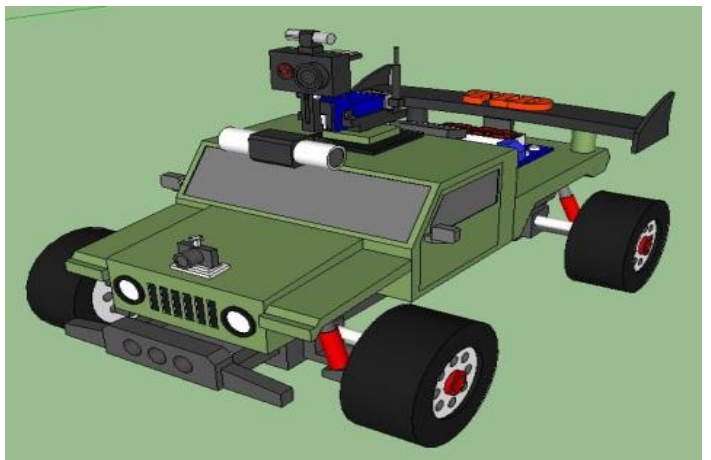

Gambar 2. Desain Alat Tampak Depan

Pada gambar 3 tampak bagian belakang robot yang dilengkapi dengan camera yang berfungsi untuk mengetahui objek yang ada di bagian belakang robot. Kemudian baterai lippo dengan tegangan 12,4 Volt 2200 mAh juga terpasang pada bagian belakang sebagai supply arus untuk sistem robot.

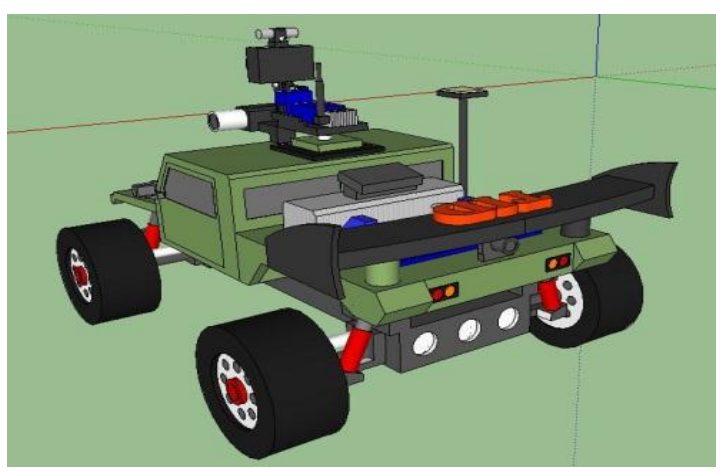

Gambar 3. Desain Alat Tampak Belakang

Gambar 4 terlihat robot menggunakan dua monitor yang akan digunakan sebagai output untuk menampilkan kondisi serta situasi yang terjadi pada saat robot diaktifkan.

Pada gambar 5, terlihat tampilan berupa kondosi atau situasi yang ada pada bagian depan robot. 
Available online at http://jurnal.stmikroyal.ac.id/index.php/jurteksi

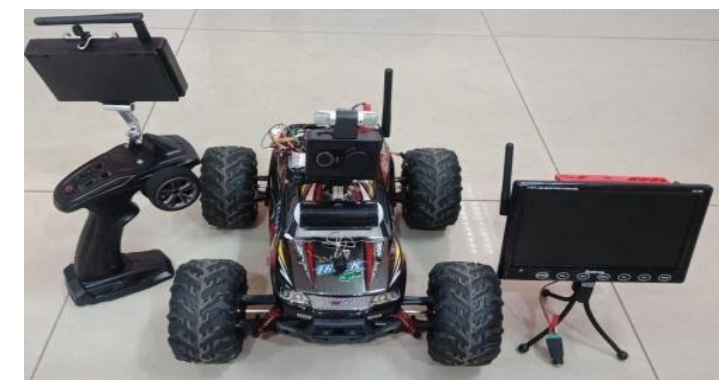

Gambar 4. Robot Pemantau Dan Negosiasi

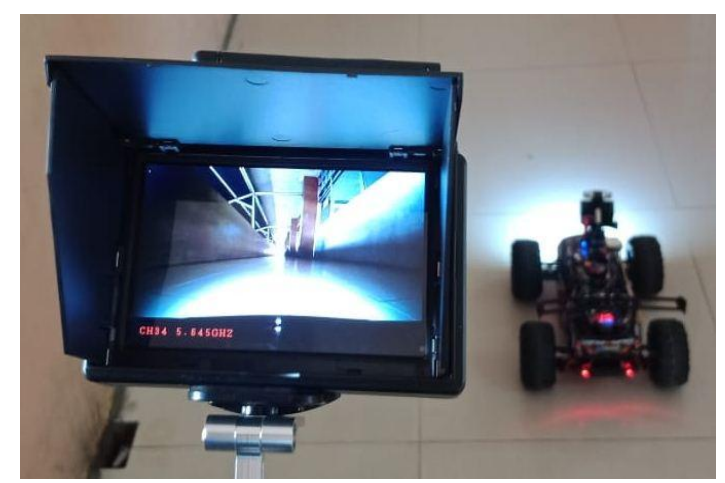

Gambar 5. Tampilan Monitor 1 Kamera Depan Robot

\section{Alur Pengiriman Data Dari Camera Ke Monitor}

Pada gambar 6 terlihat alur pengriman data mulai dari Camera FPV kemudian akan dikirimke Monitor melalui Video Sender menggunakan sinyal analog.

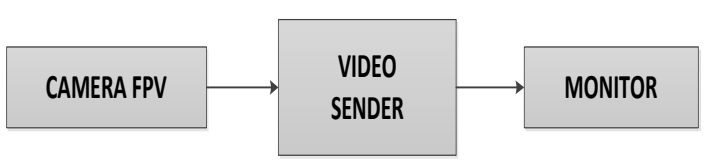

Gambar 6. Alur Pengiriman Data Dari Camera Ke Monitor

Pada bagian kamera tengah yang dilengkapi dengan servo, sehingga robot dapat memberikan informasi keadaan disekitar robot, seperti bagian kiri, kanan dan atas [11][12].

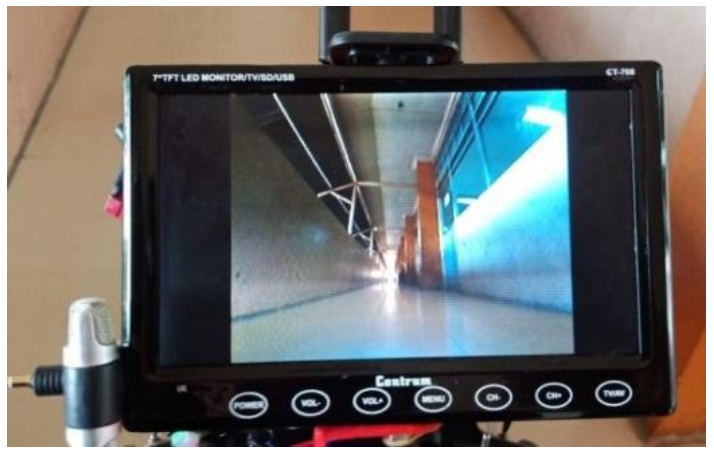

Gambar 7. Tampilan Kamera Tengah Robot

Untuk mengontrol pergerakan kamera servo akan di gerakkan melalui remote contol. Adapun cara kerja media kontrol kamera dapat dilihat pada gambar 8.

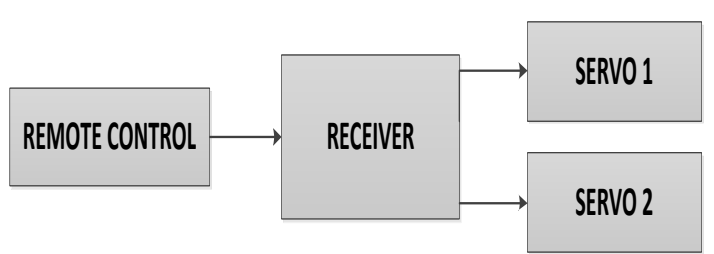

Gambar 8. Cara Kerja Pengontrol Kamera

Pada gambar 8 aliran data dimulai dari remote control ( Pergerakan kiri, kanan, atas, dan bawah ), kemudian data perintah tersebut akan dikirimkan ke receiver sehingga servo 1 dan servo 2 akan bergerak sesuai perintah dari remote control.

Selain robot mampu mengetahui situasi dan kondisi dilapangan. Robot juga dilengkapi dengan perangkat GPS [13][14]. Perangkat ini akan digunakan sebagai media untuk mengetahui posisi robot. Jika perangkat GPS diaktifkan maka robot akan mengirimkan informasi lokasi atau titik koodinat dalam bentuk SMS. 
Available online at http://jurnal.stmikroyal.ac.id/index.php/jurteksi

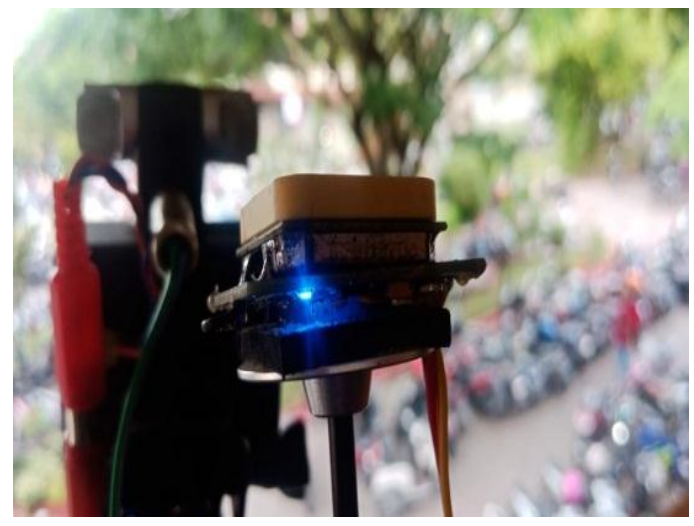

Gambar 9. Perangkat GPS

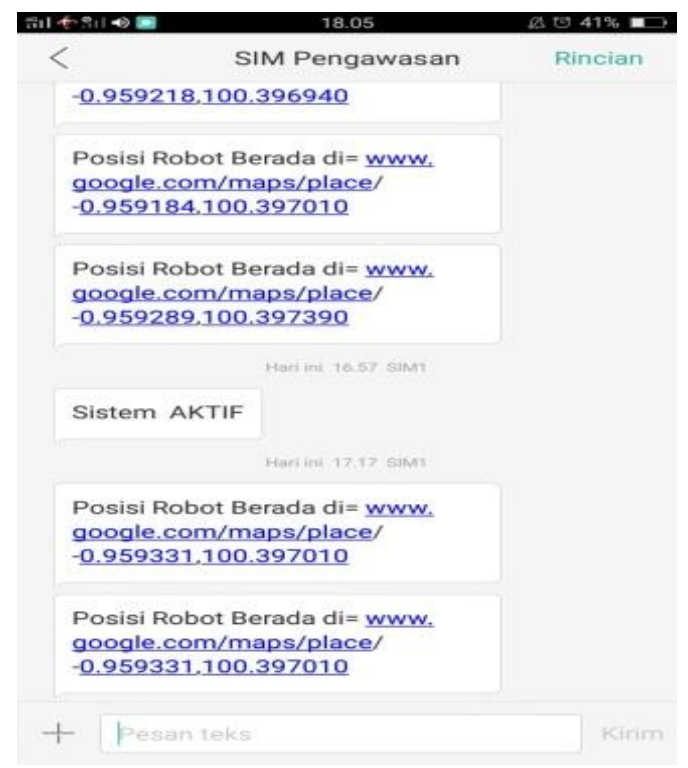

Gambar 10. Pengiriman SMS Lokasi Robot

Dalam proses negosiasi robot dilengkapi dengan Modul GSM yang akan digunakan untuk media komunikasi pada saat proses negosiasi.

Pada gambar 11 kita dapat memanfaatkan telephon selular sebagai media komunikasi dengan musuh.

Pada penelitian ini, arduino akan digunakan sebagai pusat kontrol data. Uraian hasil kerja arduino dapat dilihat pada gambar 12 .

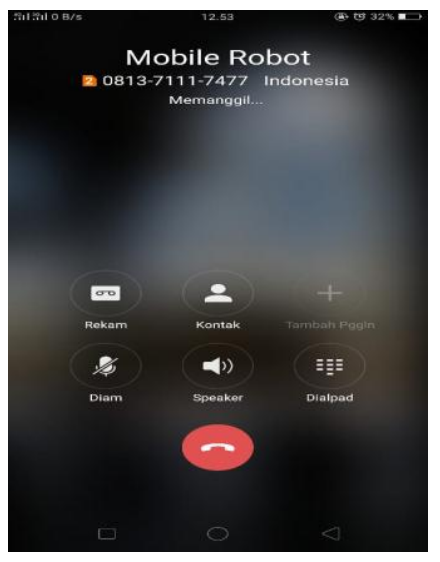

Gambar 11. Proses Calling (Mobile Robot)

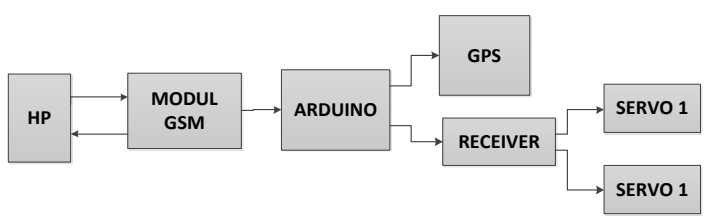

Gambar 12. Uraian Hasil Kerja Arduino

Pada gambar 12 terlihat perangkat-perangkat yang berfungsi sebagai media untuk sistem kendali robot.

\section{SIMPULAN}

Setelah dilakukan pengujian sistem, maka dapat diambil kesimpulan Dengan menggunakan camera dapat lebih memudahkan untuk mengetahui objek yang ada di bagian depan dan belakang robot dan user juga lebih berhati-hati dalam mengendalikan robot. Dengan Dibangunnya sistem Teknologi Robotik Dalam Dunia Militer Sebagai Media Pemantau Negosiasi Berbasiskan Artificial Intelligence akan lebih mempermudah dalam proses negosiasi pembebasan sandera militer, sehingga akan mengurangi resiko jatuhnya korban jiwa. 
JURTEKSI (Jurnal Teknologi dan Sistem Informasi)

Vol. 6 No. 2, April 2020, hlm. 155 - 162

DOI: https://doi.org/10.33330/jurteksi.v6i2.538

Available online at http://jurnal.stmikroyal.ac.id/index.php/jurteksi

\section{UCAPAN TERIMA KASIH}

Penulis mengucapkan terima kasih kepada Dirjen Perguruan Tinggi dan Yayasan Perguruan Tinggi Komputer Padang dan Universitas Putra Indonesia yang sudah mendanai Penelitian Terapan penulis, sehingga penulis dapat menyelesaikan penelitian ini.

\section{DAFTAR PUSTAKA}

[1] Y. Yuliza and U. N. Kholifah, "Robot Pembersih Lantai Berbasis Arduino Uno Dengan Sensor," J. Teknol. Elektro, vol. 6, no. 3, pp. 136-143, 2015.

[2] S. Sakur and A. Ubaidillah, "Sistem Kontrol Robot Pengintai Berbasis Video Sender," J. Tek. Elektro dan Komput. TRIAC2, vol. 6, no. 1, 2019.

[3] M. D. Putro and J. Litouw, "Robot Pintar Penyambut Costumer pada Pusat," J. Rekayasa Elektr., vol. 13, no. 1, pp. 8-17, 2017.

[4] I. Gunawan and I. Fathurrahman, "Prototipe Robot Pemantau Suhu Dalam Zona Kebakaran Gedung Menggunakan Telemetri Jaringan Nirkabel," Infotek J. Inform. dan Teknol., vol. 1, no. 2, pp. 107-114, 2018.

[5] D. A. Arbaus, D., Prasetya and A. P. Sari, "Kecerdasan Buatan Pada Sistem Pintu Otomatis Menggunakan Voice Recognition Berbasis Raspberry Pi," J. IlmuIlmu Tek., vol. 12, no. 3, pp. 186196, 2016.

[6] C. Halim and H. Prasetyo, "Penerapan Artificial Intelligence dalam Computer Aided Instructure (CAI)," J. Sist. Cerdas, vol. 1, no.
ISSN 2407-1811 (Print)

ISSN 2550-0201 (Online)
1, pp. 50-57, 2018.

[7] N. T. Wirawan and R. Devita, "Implementasi Algoritma Fuzzy Logic Pada Robot Arm Dengan Memanfaatkan Accelerometer Smartphone Android," JTIP J. Teknol. Inf. dan Pendidik., vol. 10, no. 2, pp. 1-12, 2017.

[8] A. Sugiharto, "Sistem Kontrol Nirkabel pada Surveillance Mobile Robot Jurnal Disprotek," $J$. Disprotek, vol. 8, pp. 8-15, 2017.

[9] R. D. Nugraha, F. Firdaus, and D. Derisma, "Rancang Bangun Mobile Robot Pengikut Manusia Berdasarkan Warna Menggunakan Metode Template Matching Berbasis Mini Pc," in Prosiding Semnastek, 2016.

[10] A. Pujayanti, "UPAYA PEMBEBASAN WNI SANDERA KELOMPOK ABU SAYYAF," Info Singk. Pus. Penelit. Badan Keahlian DPR RI, vol. 8, no. 7, 2016.

[11] J. Huang, C. Tong, J. Lang, Z. Yuan, and P. Zheng, "Analysis and Optimization of Servo Motor Control Strategy for Minimally Invasive Surgical Robot," in 22nd International Conference on Electrical Machines and Systems (ICEMS), 2019, pp. 1-6.

[12] S. Sausan et al., "Robot Pointer sebagai Penunjuk Jalan Tim SAR untuk Mempermudah Pencarian Korban Bencana Gempa," J. Rekayasa Elektr., vol. 13, no. 2, pp. 112-118, 2017.

[13] L. Rosyidi, "PERANCANGAN APLIKASI DAN SISTEM KENDALI UNTUK ROBOT PENANGGULANGAN

BENCANA ALAM," J. Teknol. terpadu, vol. 2, no. 1, 2016.

[14] A. S. Handayani, "Sistem Navigasi 
DOI: https://doi.org/10.33330/jurteksi.v6i2.538

Available online at http://jurnal.stmikroyal.ac.id/index.php/jurteksi

pada Mobile Robot dengan Global

Positioning System (GPS)," in

Annual Research Seminar (ARS),

pp. 373-376. 